\title{
ПРОБЛЕМНЫЕ АСПЕКТЫ ВВЕДЕНИЯ В ДЕЙСТВИЕ СУДЕБНЫХ УСТАВОВ 20 НОЯБРЯ 1864 г.
}

\begin{abstract}
Аннотация: Представленная к публикачии статья посвящена изучению особенностей пространственновременного распространения судебной реформы 18642. Автором уделяется внимание различным позициям, занимаемым министром юстищии Д.Н. Замятниным, Государственного Совета князем П.П. Гагариным, другими общественными и государственными деятелями и, прежде всего, самим императором, по вопросам о порядке введения Судебных Уставов 20 ноября 1864 г. Проблема введения в действие Судебных Уставов 20 ноября 1864 г. изучалась автором во взаимосвязи и взаимозависимости с другими социально-экономическими, культурно-образовательными преобразованиями, проводивщимися параллельно с реорганизацией судебной системы в пореформенный период ХІХ в. Работа строится на критическом и, вместе с тем позитивном анализе теоретического и практического материала и подчинена логике процесса внедрения пореформенных судебных учреждений в исследуемый пространственно-временной период. Применение диалектического метода познания позволило автору исследовать прочесс уничтожения «старых» судебных учреждений и создания и развития пореформенных институтов. Применение принципа историзма предоставило возможность осмыслить прочесс проведения судебной реформы 1864 г. в связи с конкретно-историческими условиями того времени. Общенаучные методы, включая в себя анализ, синтез, дедукиию, индукиию, комплексный, функииональный и другие подходы, позволили провести условное разделение такого сложного государственно-правового явления, как внедрение судебной реформы 1864 г. в правовую действительность Российского государства, на части в виде отдельных составляющих элементов пореформенной судебной системы. В настоящей работе был использован частно-научный метод, включающиий приемы и методы, позволяющие собрать, обработать и обобщить материал, составляющий источниковую базу данной работы. Научная новизна данной работы заключается в исследовании прочесса практической реализачии судебной реформы 1864 г. Автором были изучены условия, порядок и особенности пространственно-временного распространения пореформенных институтов. В научный оборот были введены новые архивные источники. В ходе исследования дана характеристика ряда проблем концептуального плана, связанных с раскрытием сущностных аспектов проведения преобразований, начавшихся в 1864 г.

Abstract: The article provided for the publication is devoted to the studies of the specific features of territorial and temporal application of the judicial reform of 1864. The author pays attention to the various positions expressed by the Minister of Justice D.N. Zamyatnin, of the State Council by the Prince P.P. Gagarin, other public and state figures, and, first of all, by the Emperor himself on the issues of bringing into force of the Judicial Charters of November 20, 1864, these positions were studied by the author in correlation and dependency with other social, economic, cultural, and educational changes, which took place in the parallel with the reorganization of the judicial system in the post-Reform period of XIX century. The article is based upon critical positive analysis of theoretical and practical material, and it follows the logic of the process of introduction of the post-reform judicial institution at the said territorial and temporal ranges. Application of the dialectic method of cognition allowed the author to study the process of destruction of the "old" judicial institutions, formation and development of the post-reform institutions. Application of the historicism principle has provided the possibility to evaluate the process of judicial reform of 1864 within the framework of specific historical conditions of the time. The general scientific methods include analysis, synthesis, deduction, induction, complex, functional and other approaches, allowing for relative distinguishing of introduction of the judicial reform of 1864 into the legal reality of the Russian state as a complicated public law matter as a set of elements of the post-reform judicial system. The article also used special scientific methods, including means and methods, allowing to gather, process and generalize the materials from the source basis for the article. The scientific novelty of the article is due to the studies of the process of practical implementation of the judicial reform of 1864. The author has studied the conditions, procedure, and specific features of the territorial and temporal range of application of post-reform institutions. New archive sources are introduced into the scientific turnover. In the process of studies the author provides characteristics of a number of conceptual problems regarding the fundamental aspects of the reforms starting in 1864.
\end{abstract}




\section{Право и политика 5 (173) • 2014}

Ключевые слова: судебная реформа, министерство юстиции, Государственный Совет, окружной суд, мировая юстиция, император, Судебные Уставы, органы местного самоуправления, сменяемость, назначаемость.

Keywords: judicial reform, ministry of justice, State Council, district court, justices of peace, Emperor, Judicial Charters, local self-government bodies, removability, assigning.

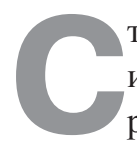

тановление судебной системы в Российской империи, основанной на началах судебной реформы 1864 г., было сопряжено со значительными проблемами, носящими формально-юридический, экономический, кадровый, морально-этический характер. Оптимальный вариант решения стоявших перед правительством задач подобного рода, вероятно, заключался в необходимости многоуровневого, поэтапного распространения положений судебной реформы 1864 г. Именно этот путь реформирования судебной системы представлялся наиболее применимым к российским условиям 60-х гг. ХІХ в. Очевидные различия в социальноэкономическом, религиозном, образовательном уровне развития регионов препятствовали созданию единой судебной системы одновременно во всем государстве.

Однако, вопрос о сроках проведения судебной реформы 1864 г. оставался открытым в правительстве и явился предметом дискуссии. Различные точки зрения по этой проблеме высказывались министром юстиции Д.Н. Замятниным и председателем Государственного Совета князем П.П. Гагариным. В свою очередь в Государственном Совете так же не было единого мнения, относительно пространственно-временного аспекта проведения реформы. Ряд его представителей «стали сомневаться в пользе одновременного введения судебных уставов во всей империи» ${ }^{1}$ Если Д.Н. Замятнин выступал за постепенное проведение в жизнь принципов, заложенных в Судебных Уставах 20 ноября 1864 г., то П.П. Гагарин отстаивал необходимость одновременного переустройства судоустройства и судопроизводства по всей стране.

В данном случае, позиция министра юстиции представляется наиболее приемлемой и дальновидной. Не случаен в связи с этим интерес к личности и государственной деятельности Д.Н. Замятнина среди современных исследователей. Ибо позиция политика, основанная на глубоком, разностороннем анализе условий проведения той или иной реформы, на прогнозировании ее последствий, представляет собой исключительно полезный опыт с политологической и юридической точек зрения.

Император, восприняв концепцию реформирования судебных учреждений в Российском государ-

\footnotetext{
${ }^{1}$ Гессен И.В. Судебная реформа. СПб., 1905. С. 124.
}

стве Д.Н. Замятнина, 19 октября 1865 г. издал указ «О введении в действие судебных преобразований в Петербургском и Московском округах» $»^{2}$ В провинциальных губерниях по данному закону Судебные Уставы 20 ноября 1864 г. не получали распространения. Следовательно, именно позиция государя имела решающее значение при определении методов реформирования судоустройства и судопроизводства в губерниях Российской империи. Государь, как высшая законодательная инстанция в данном случае действовал в единстве с министерством юстиции, то есть с исполнительной властью, что способствовало приданию органичности взаимодействию центральных государственных структур в руководстве над процессом внедрения новых начал судоустройства и судопроизводства в губерниях. Так, министерство юстиции доказало свою приверженность курсу, основанному на постепенном проведении реформы. В 1866 г. было указано, что «только система постепенного по местностям, введения сей реформы в полном ее объеме, может обеспечить надлежащее и правильное ее осуществлении» ${ }^{3}$. Подобная позиция характеризует высокую степень ответственности центральных органов власти за последствия внедрения Судебных Уставов 20 ноября 1864 г. Правительством был продуман и детально проработан, просчитан каждый шаг, каждый этап проведения реформы в губерниях и уездах огромного государства, столь значительно отличающихся друг от друга практически по всем характеристикам. Попыткам реформирования губернской судебной системы посредством, так называемой, шоковой терапии был дан решительный отпор со стороны министра юстиции и государя.

Весной 1866 г. произошло открытие окружных судов в С-Петербурге и Москве, ознаменовав собой первый этап практического применения Судебных Уставов от 20 ноября 1864 г. Действительно, столичные губернии обладали наивысшим социально-экономическим, кадровым, научным, образовательным потенциалом в государстве. В силу этих существенных

${ }^{2}$ ПСЗРИ. Изд. 2-е. - СПб.: тип. Втор. Отд. Собств. Его Имп. Вел. Канц., 1867.. Т.40. Ст. 42587.

${ }^{3}$ Судебно-статистические сведения и соображения о введении в действие Судебных Уставов 20 ноября 1864 г., ч. 1, СПб., 1866. С. 1. 
обстоятельств наиболее логически обоснованным представляется деятельность правительства относительно проведения первого этапа судебной реформы в выше названных городах.

Следующий, второй этап пространственно-временного распространения Судебных Уставов 20 ноября 1864 г. начинается в 1867 г., когда граф К.И. Пален, сменив Д.Н .Замятнина на посту министра юстиции, составил документ «О введении мировых судебных учреждений в 28 -и губерниях» ${ }^{4}$. Проведение второго этапа судебной реформы, в отличии от первого основывалось не только на формально-юридической базе, но и на практическом опыте внедрения Судебных Уставов 20 ноября 1864 г. в Санкт Петербурге и Москве. Данный фактор привел к необходимости издания правительством ряда юридических актов, призванных детализировать, уточнить, разъяснить Судебные Уставы 20 ноября 1864 г., являвшиеся основными, базовыми законами, регулировавшими проведение реформы. 26 апреля 1868 г. К.И. Пален внес в Государственный Совет представление «О дальнейшем введении судебных преобразований». Позиция министра юстиции сводилась к необходимости скорейшего введения мирового суда, как наиболее дешевого в экономическом отношении, а так же - не требовавшего наличия профессиональных юридических кадров. Мировой суд характеризовался упрощенной процедурой ведения дел, что так же способствовало скорейшему его внедрению в юридическую практику не только в столичных, но и в других губерниях Российского государства.

Министр юстиции настаивал также на назначении мировых судей правительством. Такая позиция имела косвенное обоснование в самих Судебных Уставах 20 ноября 1864 г. Так, в статье 38 «Учреждения судебных установлений» указывалось на возможность назначения недостающего числа мировых судей до следующих выборов первым департаментом Сената по представлению министра юстиции'. Однако данная статья содержит важное условие, при наличии которого мог вступить в законную силу механизм назначения мировых судей. Этим условием являлся результат выборов, в ходе которых выяснялось, что количество мировых судей не соответствовало штатному расписанию. Следовательно, только вакантные должности замещены посредством назначения правительством, а не выборов органами местного самоуправления. Отсюда видно, что стремление К.И. Палена ввести принцип комплектования

${ }^{4}$ Российское законодательство Х-ХХ вв. / Под ред. Чистякова О.И. T.8. M., 1991. C. 36. кадрового корпуса мировой юстиции, в основе которого предполагалось назначение, а не выборность противоречило содержанию статей «Учреждения судебных установлений», посвященных мировому суду. Кроме того, граф К.И. Пален предлагал назначение мировых судей на неопределенный срок 5 . Данная концепция не соответствовала статье 23 «Учреждения судебных установлений», в которой определялся срок избрания почетных и участковых мировых судей. При чем, в статье не содержался перечень каких-либо возможных обстоятельств, продлевавших или сокращавших трехлетний период пребывания мировых судей в этой должности. Следовательно, предложение о бессрочном назначении мировых судей не имело не только прямого, но даже косвенного подтверждения в Судебных Уставах 20 ноября 1864 г. В связи с этим, закономерным представляется тот факт, что позиция К.И. Палена встретила противодействие С.И. Зарудного, принявшего видное участие в процессе подготовки Судебных Уставов 20 ноября 1864 г. В воспоминаниях сенатора М.Б Веселовского мы находим такую характеристику С.И. Зарудного: «... маленький ростом, очень энергичный... он отличался многосторонностью.., занимался астрономией, цветоводством, переводил с итальянского целые книги... Он был человек искренний, прямолинейный, не любивший даже на словах поступаться своими убеждениями...» ${ }^{6}$. 30 апреля 1864 г. С.И. Зарудный представил ряд возражений на рассмотрение Государственного Совета. Основной смысл его позиции сводился к отрицанию точки зрения К.И. Палена относительно принципа назначаемости мировых судей. Государственный Совет в целом принял позицию С.И. Зарудного.

Мировой суд остался выборным институтом, как это и было предусмотрено Судебными Уставами 20 ноября 1864 г. 30 июня 1868 г. был издан указ императора, в соответствии с которым, мировые судебные установления подлежали введению в тех губерниях, где пореформенные судебные учреждения еще не были внедрены, однако, действовали земские органы местного самоуправления7. К числу этих губерний относились: Вятская, Казанская, Костромская, Олонецкая, Пензенская, Самарская, Саратовская, Симбирская, Смоленская, Тамбовская, Черниговская».

В Указе от 30 июня 1868 г. отмечается, что «Судебные установления, образованные на основании учрежден-

\footnotetext{
${ }^{5}$ РГИА. Ф. 1149. Т. VIL 1868. Д. 60. Л. 4.

${ }^{6}$ РНБ. Ф.550. Д. 861. Л.638, 638 (об.).

${ }^{7}$ ПСЗРИ. Изд.2-е. - СПб.: тип. Втор. Отд. Собств. Его Имп. Вел. Канц. 1873. Т.43. Ст. 46061
} 


\section{Право и политика $5(173) \cdot 2014$}

ных императором 20 ноября 1864 г. Уставов в округах: С. - Петербургской, Московской и Харьковской Судебных Палат, оправдали ... ожидания», возложенные императором и авторами судебной реформы, «доставив народу скорый, правильный и пользующийся общим доверием суд. Желая в ближайшем времени распространить благотворное действие нового порядка судопроизводства и на прочие части» Российской империи, государем были утверждены «составленные в Министерстве Юстиции и рассмотренные Государственным Советом предложения о введении Судебных Уставов, в течение первой трети 1869 г., в округе Одесской Судебной Палаты, с отнесением к нему на первое время губерний: Херсонской, Екатеринославской (за исключением уездов: Бахмутского и Славяно-сербского) и Таврической, а также в губерниях Полтавской и Нижегородской». Государь император повелел так же немедленно приступить «к введению мировых судебных установлений во всех губерний, на которые действие Уставов 20 ноября 1864 г. еще не распространяется, но где образованы земские учреждения на основании утвержденного 1 января 1864 г. Положения, именно в губерниях: Вятской, Казанской, Костромской, Олонецкой, Пензенской, Самарской, Саратовской, Симбирской, Смоленской, Тамбовской (за исключением вошедших уже в состав Харьковского округа уездов: Липецкого, Лебедянского и Усманского) и Черниговской». Мировые суды подлежали введению «с соблюдением следующих правил: 1 . Мировые судебные установления открываются в этих местностях на точном основании Судебных Уставов 20 ноября 1864 г. и Положения 19 октября 1865 г. о введении Уставов в действие. 2. Время введения в действие мировых судебных установлений в каждой губернии определяется министром юстиции по соглашению с министрами внутренних дел и финансов. 3. С открытием мировых установлений в губернии, суды первой степени», действовавшие ранее, «упраздняются, а Палаты Гражданского и Уголовного Суда губернии соединяются в одну Палату Уголовного и Гражданского Суда, в которой и начинают непосредственно» рассматриваться «все дела, изъятые из ведомства мировых судей. Дела эти производятся в Палатах по правилам, установленным» в Высочайше «утвержденном мнении Государственного Совета 11 октября 1865 г. и в изданных в дополнение к нему узаконениях. 4. Для исполнения ... в отношении мировых судебных установлений обязанностей, которые по Судебным Уставам возложены на Товарищей Прокурора Окружного Суда, учреждаются временно Товарищи Губернского Прокурора ... Они исполняют, по его распределению, и все остающиеся в силе обязанности Губернских и Уездных Стряпчих, должности которых упраздняются. 5. Права и обязанности в отношении мировых судебных установлений, принадлежащие по Судебным Уставам Судебным Палатам, возлагаются на существующие Судебные Палаты по временному распределению губерний между палатами, которое министру юстиции предоставляется составить и изменять по мере открытия новых судебных палат. 6 ... О распределении обязанностей уездных Судов и порядке окончания производящихся в них дел с упразднением этих судов по введению мировых судебных установлений, а также о порядке разрешения пререканий (прим. автора споров) о подсудности между мировыми судьями и судебными следователями, впредь до учреждения окружных судов, будут изданы особые правила. Правительствующий Сенат» сделает надлежащие распоряжения.

Таким образом, процесс теоретического обсуждения путей внедрения Судебных Уставов 20 ноября 1864 г. привел к необходимости некоторой трансформации принципов внедрения пореформенных судебных учреждений, в частности, выразившейся в поэтапном проведении судебной реформы, во введении мировой судебных учреждений отдельно от общих в целом ряде губерний. Эти тенденции были законодательно оформлены и обоснованы комплексом факторов как объективного, так и субъективного плана. Наряду с существенной социально-экономической неоднородностью, присущей различным губерниям, не менее важным аспектом явилась позиция определенного круга государственных деятелей, препятствовавших становлению судебной системы на началах, заложенных в Судебных уставах 20 ноября 1864 г.

\section{Библиография:}

1. Гессен И.В. Судебная реформа. Великие реформы 60 -х гг. в их прошлом и настоящем / ред. И.В. Гессен. - СПб.: типо-лит. Ф.Вайсберга и П. Гершунина, 1905. 267 с.

2. Чистяков О.И. Российское законодательство $\mathrm{X}-\mathrm{XX}$ веков: Судебная реформа. В 9-ти томах. Т. 8 / Отв. ред.: Виленский Б.В.; Под общ. ред.: Чистяков О.И. - М.: Юрид. лит., 1991.- 496 с.

3. Д.А. Полещенко. Основные юридические концепции соотношения и взаимодействия государственной власти и местного самоуправления, разрабатываемые в Российской Империи (1864-1917 гг.) // Политика и Общество. - 2010. - № 6. 
4. А. Ю. Корчагин, Л. Г. Свечникова, С. В. Шевченко. Проведение судебной реформы 1864 года в Ставропольской губернии. // Право и политика. - 2009. - № 3.

5. С. В. Кодан Попытки создания Основных законов Российской империи в политике, идеологии и юридической практике Российского государства (XVIII - начало XIX вв.) // Право и политика. 2012. - 3. - C. 560-569. 122

6. С. А. Февралёв Местное законодательство в государственно-правовом развитии России (вторая половина XVII - начало XX вв.) // Право и политика. - 2011. - 7. - C. 1171-1181.

7. Т. М. Баженова, С. В. Кодан - К 175-летию издания Свода законов Российской империи. Свод законов Российской империи в правовом развитии России// Право и политика, №1-2008

8. Кодан С. В. Политико-юридическая методология в исследовании истории модернизации государственно-правовой системы России (XIX - начало ХХ вв.)//Политика и Общество, №3-2012

9. Кодан С. В. Сословная стратификация общества и законодательство о состояниях в политике российской верховной власти (1800-1850-е гг.)//Политика и Общество, №9-2012

10. Борисовский Е. Е. Отечественная либеральная политико-правовая мысль конца XVIII - начала XIX вв.: И.П. Пнин и К.Ф. Герман//Политика и Общество, №12-2011

11. Щедрина Ю.В. Обеспечение независимости судей специальных (сословных) судов в России в 60-е - 80-е гг. XIX в.: проблемы правового регулирования (на примере духовного суда)//Политика и Общество, №11-2012

12. Федорец А. И. Московское купечество XVIIIXIX веков в зеркале исповедных ведомостей (на примере рода Третьяковых)//Исторический журнал: научные исследования, №4-201

13. Кодан С.В., Февралёв С.А. Местное право Прибалтики в правовой системе Российской Империи: интеграция, систематизация, унификация (XVIII - начало XX вв.) // NB: Вопросы права и политики. - 2013. - 7. - C. 125-147. DOI: 10.7256/2305-9699.2013.7.626. URL: http://www.enotabene.ru/lr/article_626.html

14. Кодан С.В., Февралёв С.А. Состояние, развитие и унификация местного права Малороссии и западных губерний (вторая половина XVII - первая половина XIX вв.) // NB: Вопросы права и политики. - 2013. - 5. - С. 268-295. DOI: 10.7256/2305-
9699.2013.5.579. URL: http://www.e-notabene.ru/lr/ article_579.html

15. Кодан С.В., Февралёв С.А. Местное право Великого Княжества Финляндского в правовой системе Российской Империи: интеграция, источники, трансформации (1808-1917 г.) // NB: Вопросы права и политики. - 2013. - 3. - С. 258-317. DOI: 10.7256/2305-9699.2013.3.498. URL: http://www.e-notabene.ru/lr/article_498.html

16. Кодан С.В., Февралёв С.А. Местное право Царства Польского: формирование, источники, трансформации (1815-1917 гг.) // NB: Проблемы общества и политики. - 2013. - 3. - C. 246-295. DOI: 10.7256/2306-0158.2013.3.468. URL: http://www.enotabene.ru/pr/article_468.html

17. Кодан С.В., Февралёв С.А. Формирование и развитие местного права в бессарабии в составе Российской Империи (1812-1917 гг.) // NB: Вопросы права и политики. - 2013. - 4. - C. 230-285. DOI: 10.7256/2305-9699.2013.4.502. URL: http://www.enotabene.ru/lr/article_502.html

18. Кодан С.В., Февралёв С.А. Местное гражданское право Грузии в правовом регулировании на Кавказе (1800-1850-е гг.) // NB: Вопросы права и политики. - 2013. - 6. - C. 197-219. DOI: 10.7256/23059699.2013.6.613. URL: http://www.e-notabene.ru/lr/ article_613.html

19. Кодан С.В. Политико-юридический подход в исследовании государственно-правового развития России (XIX - начало XX вв.) // NB: Проблемы общества и политики. - 2012. - 2. - С. 88-117. URL: http://www.e-notabene.ru/pr/article_177.html

20. Кодан С.В. Система законодательства в России: формирование, развитие, становление (IX - начало XX вв.) // NB: Проблемы общества и политики. - 2013. - 4. - C. 239-293. DOI: 10.7256/23060158.2013.4.436. URL: http://www.e-notabene.ru/pr/ article_436.html

21. С. А. Февралёв Политико-юридическая природа местного права в Российской империи (вторая половина XVII - начало XX вв.). // Право и политика. - 2012. - 2. - C. 327-338.

22. С.В. Кодан Систематизация местных узаконений прибалтийских губерний Российской империи (1720-1860-е гг.) // Политика и Общество. - 2013. - 1. - C. 108-120. DOI: 10.7256/1812 8696.2013.01.14.

23. Кодан С.В., Владимирова Г.Е. Юридическая природа Основных государственных законов Российской империи 1832-1892 гг. издания в оценке российских 


\section{Право и политика $5(173) \cdot 2014$}

правоведов // NB: Проблемы общества и политики. - 2013. - 6. - С. 218-253. DOI: 10.7256/23060158.2013.6.765. URL: http://www.e-notabene.ru/pr/ article_765.htm

24. Кодан С.В., Февралёв С.А. Местное право национальных регионов Российской Империи: истоки, место в политике и идеологии, юридическая природа (вторая половина XVII-начало XX вв.) // NB: Вопросы права и политики. - 2013. - 2. - С. 74-154. DOI: 10.7256/2305-9699.2013.2.464. URL: http:// www.e-notabene.ru/lr/article_464.htm

25. Ю. В. Щедрина Несменяемость судей в России во второй половине 60-х-конце 80-х гг. ХІХ в.: законодательное закрепление и практика реализации // Право и политика. - 2012. - 9. - С. 1618 - 1627.

26. Ю.В. Щедрина Обеспечение независимости судей специальных (сословных) судов в России в 60 -е - 80-е гг. ХІХ в.: проблемы правового регулирования (на примере духовного суда) // Политика и Общество. - 2012. - 11. - С. 126 - 133.

27. Щедрина Ю.В. Кадровые полномочия губернаторов в сфере судебного управления в России в $1860-x$ - середине 1880-х гг. (к вопросу о независимости судей) // Административное и муниципальное право. - 2012. - 11. - С. $44-53$.

28. Щедрина Ю.В. Социально-правовые гарантии независимости судей в России в $1860-\mathrm{x}-1890$-х гг. // Право и политика. - 2014. - 2. - С. 207 - 218. DOI: 10.7256/1811-9018.2014.2.10892.

29. Береговая Е.В. Мировая юстиция в российской политической системе (по материалам социологического исследования) // Политика и Общество. - 2013. - 8. - C. 988 - 993. DOI: 10.7256/18128696.2013.8.9086.

\section{References (transliteration):}

1. Gessen I.V. Sudebnaya reforma. Velikie reformy $60-\mathrm{khgg}$. $\mathrm{v}$ ikh proshlom i nastoyashchem / red. I.V. Gessen. $\mathrm{SPb}$.: tipo-lit. F.Vaisberga i P. Gershunina, 1905. $267 \mathrm{~s}$.

2. Chistyakov O.I. Rossiiskoe zakonodatel'stvo X-XX vekov: Sudebnaya reforma. V 9-ti tomakh. T. 8 / Otv. red.: Vilenskii B.V.; Pod obshch. red.: Chistyakov O.I. - M.: Yurid. lit., 1991.- 496 c.

3. D.A. Poleshchenko. Osnovnye yuridicheskie kontseptsii sootnosheniya i vzaimodeistviya gosudarstvennoi vlasti i mestnogo samoupravleniya, razrabatyvaemye v Rossiiskoi Imperii (1864-1917 gg.) // Politika i Obshchestvo. - 2010. - № 6 .
4. A. Yu. Korchagin, L. G. Svechnikova, S. V. Shevchenko. Provedenie sudebnoi reformy 1864 goda v Stavropol'skoi gubernii. // Pravo i politika. - 2009. - № 3.

5. S. V. Kodan Popytki sozdaniya Osnovnykh zakonov Rossiiskoi imperii v politike, ideologii i yuridicheskoi praktike Rossiiskogo gosudarstva (XVIII - nachalo XIX vv.) // Pravo i politika. - 2012. - 3. - C. 560-569. 122

6. S. A. Fevralev Mestnoe zakonodatel'stvo v gosudarstvenno-pravovom razvitii Rossii (vtoraya polovina XVII - nachalo XX vv.) // Pravo i politika. - 2011. 7. - C. 1171-1181.

7. T. M. Bazhenova, S. V. Kodan-K 175-letiyu izdaniya Svoda zakonov Rossiiskoi imperii. Svod zakonov Rossiiskoi imperii v pravovom razvitii Rossii//Pravo i politika, №1-2008

8. Kodan S. V. Politiko-yuridicheskaya metodologiya $\mathrm{v}$ issledovanii istorii modernizatsii gosudarstvennopravovoi sistemy Rossii (XIX - nachalo XX vv.)// Politika i Obshchestvo, №3-2012

9. Kodan S. V. Soslovnaya stratifikatsiya obshchestva i zakonodatel'stvo o sostoyaniyakh $\mathrm{v}$ politike rossiiskoi verkhovnoi vlasti (1800-1850-e gg.)//Politika i Obshchestvo, №9-2012

10. Borisovskii E. E. Otechestvennaya liberal'naya politiko-pravovaya mysl' kontsa XVIII - nachala XIX vv.: I.P. Pnin i K.F. German//Politika i Obshchestvo, №12-2011

11. Shchedrina Yu.V. Obespechenie nezavisimosti sudei spetsial'nykh (soslovnykh) sudov v Rossii v 60-e - 80-e gg. XIX v.: problemy pravovogo regulirovaniya (na primere dukhovnogo suda)//Politika i Obshchestvo, №11-2012

12. Fedorets A. I. Moskovskoe kupechestvo XVIII-XIX vekov $\mathrm{v}$ zerkale ispovednykh vedomostei (na primere roda Tret'yakovykh)//Istoricheskii zhurnal: nauchnye issledovaniya, №4-201

13. Kodan S.V., Fevralev S.A. Mestnoe pravo Pribaltiki $\mathrm{v}$ pravovoi sisteme Rossiiskoi Imperii: integratsiya, sistematizatsiya, unifikatsiya (XVIII - nachalo XX vv.) // NB: Voprosy prava i politiki. - 2013. - 7. C. 125-147. DOI: 10.7256/2305-9699.2013.7.626. URL: http://www.e-notabene.ru/lr/article_626.html

14. Kodan S.V., Fevralev S.A. Sostoyanie, razvitie i unifikatsiya mestnogo prava Malorossii i zapadnykh gubernii (vtoraya polovina XVII - pervaya polovina XIX vv.) // NB: Voprosy prava i politiki. - 2013. - 5. C. 268-295. DOI: 10.7256/2305-9699.2013.5.579. URL: http://www.e-notabene.ru/lr/article_579.html

15. Kodan S.V., Fevralev S.A. Mestnoe pravo Velikogo Knyazhestva Finlyandskogo v pravovoi sisteme 
DOI: $10.7256 / 1811-9018.2014 .5 .11861$

При цитировании этой статьи сноска на doi обязательна

История государства и права

Rossiiskoi Imperii: integratsiya, istochniki, transformatsii (1808-1917 g.) // NB: Voprosy prava i politiki. - 2013. - 3. - C. 258-317. DOI: 10.7256/23059699.2013.3.498. URL: http://www.e-notabene.ru/lr/ article_498.html

16. Kodan S.V., Fevralev S.A. Mestnoe pravo Tsarstva Pol"skogo: formirovanie, istochniki, transformatsiI (1815-1917 gg.) // NB: Problemy obshchestva i politiki. - 2013. - 3. - C. 246-295. DOI: 10.7256/23060158.2013.3.468. URL: http://www.e-notabene.ru/pr/ article $468 . \mathrm{html}$

17. Kodan S.V., Fevralev S.A. Formirovanie i razvitie mestnogo prava v Bessarabii v sostave Rossiiskoi Imperii (1812-1917 gg.) // NB: Voprosy prava i politiki. - 2013. -4. - C. 230-285. DOI: 10.7256/2305-9699.2013.4.502. URL: http://www.e-notabene.ru/lr/article_502.html

18. Kodan S.V., Fevralev S.A. Mestnoe grazhdanskoe pravo Gruzii v pravovom regulirovanii na Kavkaze (18001850-e gg.) // NB: Voprosy prava i politiki. - 2013. -6. - C. 197-219. DOI: 10.7256/2305-9699.2013.6.613. URL: http://www.e-notabene.ru/lr/article_613.html

19. Kodan S.V. Politiko-yuridicheskii podkhod v issledovanii gosudarstvenno-pravovogo razvitiya Rossii (XIX - nachalo XX vv.) // NB: Problemy obshchestva i politiki. - 2012. - 2. - C. 88-117. URL: http://www.enotabene.ru/pr/article_177.html

20. Kodan S.V. Sistema zakonodatel'stva v Rossii: formirovanie, razvitie, stanovleniE (IX - nachalo XX vv.) // NB: Problemy obshchestva i politiki. - 2013. - 4. C. 239-293. DOI: 10.7256/2306-0158.2013.4.436. URL: http://www.e-notabene.ru/pr/article_436.html

21. S. A. Fevralev Politiko-yuridicheskaya priroda mestnogo prava $\mathrm{v}$ Rossiiskoi imperii (vtoraya polovina XVII - nachalo XX vv.). // Pravo i politika. - 2012. - 2. - C. 327-338.

22. S.V. Kodan Sistematizatsiya mestnykh uzakonenii pribaltiiskikh gubernii Rossiiskoi imperii (1720- 1860-e gg.) // Politika i Obshchestvo. - 2013. - 1. C. 108-120. DOI: 10.7256/1812 - 8696.2013.01.14.

23. Kodan S.V., Vladimirova G.E. Yuridicheskaya priroda Osnovnykh gosudarstvennykh zakonov Rossiiskoi imperii 1832-1892 gg. izdaniya v otsenke rossiiskikh pravovedov // NB: Problemy obshchestva i politiki. -2013. -6. - C. 218-253. DOI: 10.7256/2306-0158.2013.6.765. URL: http://www.e-notabene.ru/pr/article_765.htm

24. Kodan S.V., Fevralev S.A. Mestnoe pravo natsional'nykh regionov Rossiiskoi Imperii: istoki, mesto $\mathrm{v}$ politike i idelogii, yuridicheskaya priroda (vtoraya polovina XVII - nachalo XX vv.) // NB: Voprosy prava i politiki. - 2013. - 2. - C. 74-154. DOI: 10.7256/23059699.2013.2.464. URL: http://www.e-notabene.ru/lr/ article_464.htm

25. Yu. V. Shchedrina Nesmenyaemost' sudei v Rossii vo vtoroi polovine $60-\mathrm{kh}$-kontse $80-\mathrm{kh}$ gg. XIX v.: zakonodatel'noe zakreplenie i praktika realizatsii // Pravo i politika. - 2012. - 9. - C. 1618 - 1627.

26. Yu.V. Shchedrina Obespechenie nezavisimosti sudei spetsial'nykh (soslovnykh) sudov v Rossii v 60-e - 80-e gg. XIX v.: problemy pravovogo regulirovaniya (na primere dukhovnogo suda) // Politika i Obshchestvo. - 2012. - 11. - C. $126-133$.

27. Shchedrina Yu.V. Kadrovye polnomochiya gubernatorov v sfere sudebnogo upravleniya v Rossii v 1860-kh - seredine 1880-kh gg. (k voprosu o nezavisimosti sudei) // Administrativnoe i munitsipal'noe pravo. 2012. - 11. - C. $44-53$.

28. Shchedrina Yu.V. Sotsial'no-pravovye garantii nezavisimosti sudei v Rossii v 1860-kh - 1890-kh gg. // Pravo i politika. - 2014. - 2. - C. 207 - 218. DOI: 10.7256/1811-9018.2014.2.10892.

29. Beregovaya E.V. Mirovaya yustitsiya v rossiiskoi politicheskoi sisteme (po materialam sotsiologicheskogo issledovaniya) // Politika i Obshchestvo. -2013. - 8. - C. 988 - 993. DOI: 10.7256/1812-8696.2013.8.9086. 